\title{
Skeletal growth and density patterns of two Porites corals from the Gulf of Eilat, Red Sea
}

\author{
R. Klein, Y. Loya \\ George S. Wise Faculty of Life Sciences, Department of Zoology, Tel Aviv University, Ramat Aviv 69978, Israel
}

\begin{abstract}
X-radiographs of vertical sections of Porites colonies ( $P$. lobata and $P$. columnaris) from coral reefs of the northern Red Sea were examined for their linear growth rate and skeletal density patterns. Results provide the first sclerochronological record of Red Sea corals. Corals sampled from the same area showed marked variations in their linear growth rate. Average growth rates were $7.48 \pm$ $1.78 \mathrm{~mm} \mathrm{yr}^{-1}$ for $P$. lobata and $5.68 \pm 1.52 \mathrm{~mm} \mathrm{yr}^{-1}$ for $P$. columnaris. High density deposition bands occur during winter (December to May; low light intensity and seawater temperature), and low density deposition bands during summer (June to November; high light intensity and seawater temperature). A model that relates exogenic factors (e.g. temperature and light) and an endogenic factor (e.g. reproduction) to the density band depositional pattern is presented. It is concluded that in the Red Sea water temperature and light intensity are the major factors controlling the identity of band formation in Porites corals, while reproduction is probably of lesser importance.
\end{abstract}

\section{INTRODUCTION}

Skeletal band couplets of alternating high density (HD) and low density (LD) in massive coral species have been used to interpret their growth history (Knutson et al. 1972, Dodge \& Vaisnys 1975). X-radiographs of vertical sections along the growth axis can be used to display the density variations (Knutson et al. 1972, Barnes \& Lough 1989). It is widely accepted that the 2 bands, low (LD) and high density (HD), represent 1 yr of growth (Buddemeier et al. 1974, Dodge \& Thomson 1974, Macintyre \& Smith 1974, Moore \& Krishnaswami 1974).

The literature contains many examples of possible correlations between the identity of the bands (e.g. low or high density) and environmental factors, such as seasonal variations in seawater temperature (Dodge \& Vaisnys 1975, Weber et al. 1975, Hudson et al. 1976) and light intensity (Buddemeier \& Kinzie 1975, Wellington \& Glynn 1983). Highsmith (1979), who examined the growth bands in relation to their time of deposition on a global scale, proposed a model relating the interplay of light availability and water temperature to the production of the different skeletal bands. Turbidity and sedimentation (Dodge \& Vaisnys 1980) and the endogenic factor of reproduction (Wellington \& Glynn 1983) were also invoked in attempts to explain the banding appearance.
Lough \& Barnes (1990) indicated the problems in density pattern interpretation, and pointed out potential sources of error, such as subjective observation, technique, and coral geometry. By listing the intraannual timing of growth bands in various corals from different reef locations, they found few exceptions to the general rule that LD bands are formed during the period of lower water temperature. Most of the exceptions according to this list were corals of the genus Porites.

Although skeletal band studies have been conducted for many years in different reef sites around the world, there is no information available on the density patterns of corals from the Red Sea. Of particular interest is the Gulf of Eilat, exhibiting one of the northern border distributions of diverse coral communities (Loya \& Slobodkin 1971). In this paper we examine the sclerochronological record of 2 Red Sea massive Porites species with regard to linear growth rates, skeletal band depositional patterns, reproductive cycle and a possible relationship of these factors to seasonality and environmental conditions. The genus Porites was chosen for this study as it exhibits (1) a small polyp diameter which provides distinct banding in X-radiographs; (2) a wide range of colony sizes; (3) high abundance throughout the Red Sea; and (4) a cosmopolitan distribution, so that it is widely studied. 


\section{MATERIALS AND METHODS}

Colonies of 2 Porites species, $P$. columnaris $(\mathrm{n}=10$ ) and $P$. lobata $(\mathrm{n}=11)$, were collected from the northern part of the Red Sea, Gulf of Eilat from 1986 to 1988 Tissue was removed using a water-jet ('water-pik') system and then the corals were dried in the sun. Thin slices ( 5 to $6 \mathrm{~mm}$ thick) were cut along the maximal growth axis with a diamond rock saw. The vertical axis was marked in situ to avoid errors of the cutting angle. The slices were X-rayed using a Phillips medical radiography machine with exposure conditions of $50 \mathrm{kVp} / 200 \mathrm{mAs}$, and a distance of $100 \mathrm{~cm}$ onto an Agfa Currix RP-2 non-screen film. For densitometry scanning we used a laser beam LKB Ultroscan II densitometer The $\mathrm{X}$-ray negatives were scanned along the maximal growth axis, and the colonies' ages were determined according to their X-ray images, with the aid of densitometry scanning. Mean geometric radius $(\bar{r})$ was computed according to Loya (1976), for comparing size vs age of the coral.

The reproduction season was detected by a histology procedure on decalcified coral samples. The samples were collected on a monthly basis during 1986 and 1987 , fixed in $4 \%$ buffered seawater formalin, and later transferred to $70 \%$ methyl alcohol. Detailed procedures are described in Rinkevich \& Loya (1979). The reproductive development was recorded and described as the increase in oocyte diameter over time. Relevant climatic data for the Gulf of Eilat were obtained from the Israeli Meteorological Station at Beit-Dagan. Light intensity was measured as sun irradiance (sunshine hours per month), and seawater temperatures were measured in the shallow water of Eilat, at a depth of about $0.5 \mathrm{~m}$.

\section{RESULTS}

The wide, bright bands (Fig. 1) represent the LD portion of the coral, while the narrower, dark bands represent the HD portion. The width of the $\mathrm{LD}$ and $\mathrm{HD}$ bands together represents the annual growth rate. The average linear growth rate (LGR) for Porites columnaris was found to be $5.68 \pm 1.52 \mathrm{~mm} \mathrm{yr}^{-1}$, while that of $P$. lobata was significantly higher, $7.48 \pm 1.78 \mathrm{~mm} \mathrm{yr}^{-1}(t$ test, $\mathrm{p}<0.05$; Table 1). For each species, 2-way ANOVA was conducted to determine possible differences in linear growth rates among various colonies, or between years of growth (1972 to 1986) within each

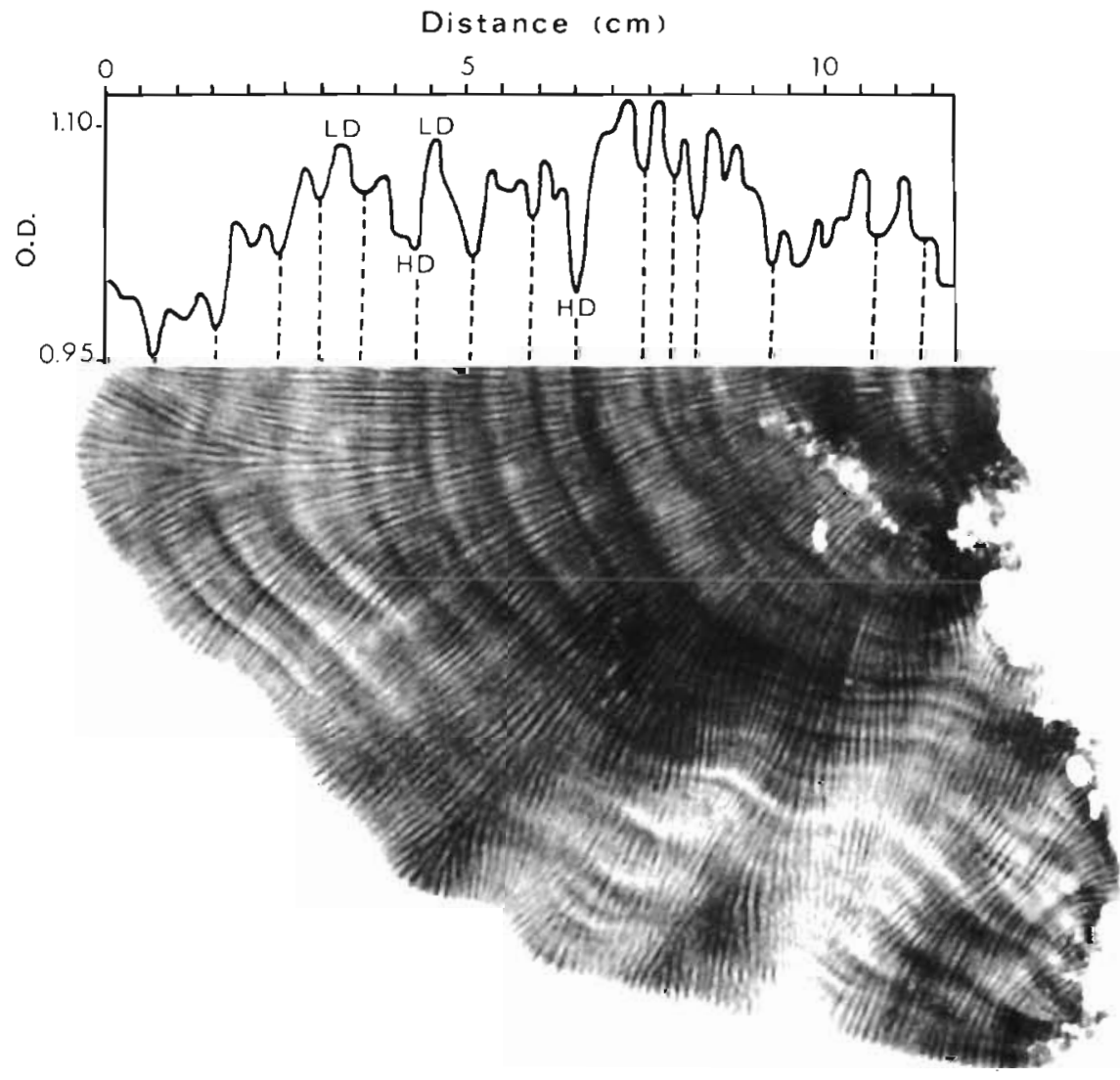

Fig. 1 Porites lobata. Distinct annual growth bands of coral revealed from X-radiograph (positive) of a vertical cross section through the colony. Wide light bands represent the LD (low density) portion of the coral, while the narrower dark bands represent the HD (high density) portion. The densitometer scanning in O.D. (optical density) units is attached to the $\mathrm{X}$-radiograph and illustrates the position of each band type along the growth protile. The dashed lines point to the most distinct HD bands. Note that high optical values correspond to low values of the skeletal density (LD) and vice versa 
Table 1. Porites spp. Averages of the linear growth rate $( \pm S D)$. n: number of years; LGR: linear growth rate $\left(\mathrm{mm} \mathrm{yr}^{-1}\right)$

\begin{tabular}{|c|c|c|c|c|c|}
\hline \multicolumn{3}{|c|}{ P. lobata } & \multicolumn{3}{|c|}{ P. columnaris } \\
\hline Coral sample & $\operatorname{LGR}\left(\mathrm{mm} \mathrm{yI}^{-1}\right)$ & $\mathrm{n}$ & Coral sample & $\mathrm{LGR}\left(\mathrm{mm} y \mathrm{r}^{-1}\right)$ & $\mathrm{n}$ \\
\hline S1 & $6.65 \pm 1.44$ & 25 & $\mathrm{G} 2$ & $6.20 \pm 1.07$ & 15 \\
\hline S2 & $6.91 \pm 1.62$ & 29 & G7 & $4.72 \pm 0.90$ & 17 \\
\hline S3 & $6.88 \pm 1.29$ & 18 & $\mathrm{Z1}$ & $4.83 \pm 1.26$ & 21 \\
\hline$\$ 4$ & $6.38 \pm 0.88$ & 23 & $\mathrm{Z} 2$ & $5.82 \pm 1.16$ & 22 \\
\hline S5 & $8.24 \pm 1.94$ & 11 & $\mathrm{Z4}$ & $4.14 \pm 1.02$ & 38 \\
\hline G1 & $4.82 \pm 1.26$ & 15 & TEM1 & $6.75 \pm 1.35$ & 6 \\
\hline G6 & $7.33 \pm 2.45$ & 12 & TEM2 & $6.44 \pm 0.93$ & 17 \\
\hline G3 & $7.93 \pm 1.56$ & 15 & TEM4 & $5.26 \pm 0.38$ & 5 \\
\hline ALT2 & $9.36 \pm 2.30$ & 13 & $\mathrm{BP} 1$ & $5.50 \pm 1.42$ & 22 \\
\hline ALT3 & $8.14 \pm 1.34$ & 17 & $\mathrm{BP} 3$ & $6.19 \pm 1.59$ & 16 \\
\hline ALT4 & $8.14 \pm 1.69$ & 15 & & & \\
\hline
\end{tabular}

colony. In both species no significant difference was found for growth rates in different years $(p>0.001)$. The mean annual growth rate did not show a determinate trend $(p<0.001)$. A significant difference in annual growth rates was observed among the various colonies due to the anomalous growth rate of colonies G1 and ALT2 of $P$. lobata, and Z4 of $P$. columnaris (Table 1, a posteriori Student-Newman-Keuls test, $\alpha=$ $0.05)$. The difference in the annual growth rates between the 2 Porites species is illustrated in Fig. 2.

The geometric mean radius $(\bar{r})$ was used as an indicator of colony size. Regression lines of the geometric mean radius $(\bar{r})$ of each colony vs colony age $(X)$ were computed for the 2 species (Fig. 3). The regression equation for Porites lobata is $\bar{r}=2.13+0.248 \times\left(\mathrm{r}^{2}=\right.$ $0.73)$ and for $P$. columnaris $\bar{r}=0.191+0.226 \times\left(\mathrm{r}^{2}=\right.$ $0.7)$. Comparison of the regression slopes of the 2 species showed no significant difference $(p>0.05)$.

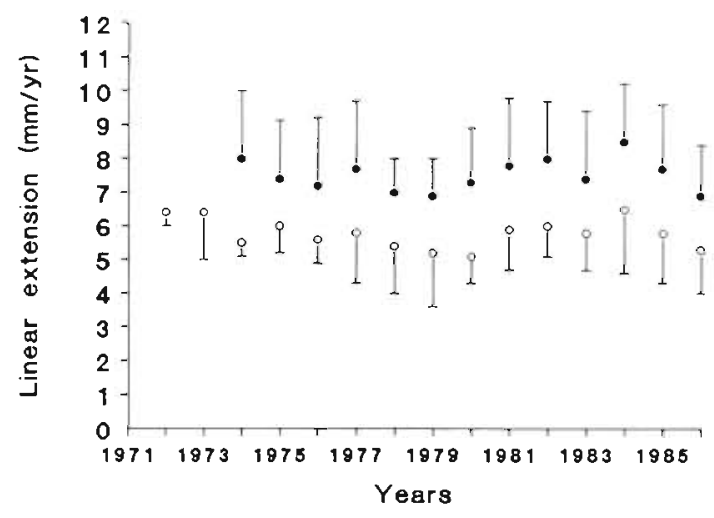

Fig. 2. Porites spp. Averages of the annual linear extension of $P$. lobata ( $\bullet \mathrm{n}=11$ colonies) and $P$. columnaris $(0 ; \mathrm{n}=10$ colonies) ( $\pm \mathrm{SD}$ ) in the years 1972 to 1986 . Details on the number of growth years measured within each colony are given in Table 1

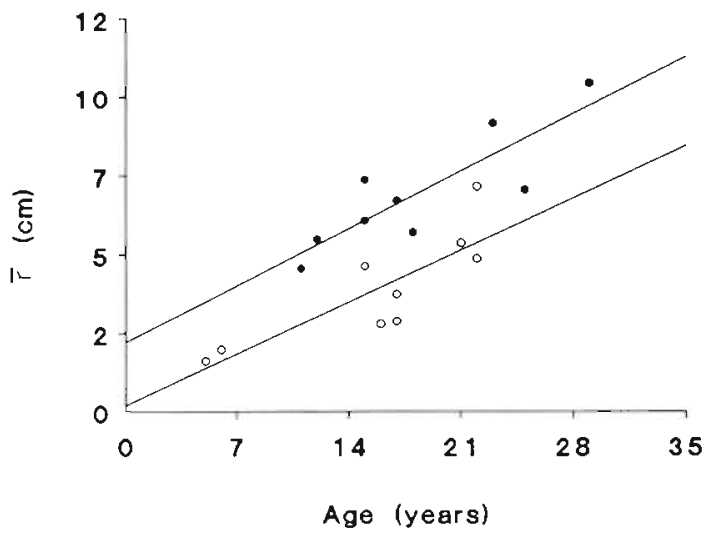

Fig. 3. Porites spp. Regression lines of size (geometric mean radius, $\bar{r}$ ) versus age in $P$. lobata $(\bullet)$ and $P$. columnaris (o)

The identity of the outermost band and the date of collection were used as base line information to determine the seasonality of band formation. The timing of band deposition based on 2 seasonal sampling periods is summarized in Table 2 and further illustrated in Table 3 . The ratio $x / y$ (Table 2 ) represents the percentage of the outermost band type compared to the total average (LD or $\mathrm{HD}$ respectively), which gives an approximate estimate of the duration of deposition of this band. As indicated by these tables, the wide LD bands are deposited during summer, between June and November, while the narrow HD bands are deposited during winter, between December and May.

Histological analysis of the 2 Porites species indicated that the reproductive period occurs between March and July. The oocytes reach their maximum diameter (90 to $100 \mu \mathrm{m}$ ) towards the end of June and in both species are released to the water during July (Fig. 4). The exact time of oocyte release for each species is yet to be determined. 
Table 2. Porites spp. Timing of band deposition according to type and width of the outermost band obtained in the X-ray image. The ratio $x / y$ represents the percentage of the outermost band of the total LD or HD average. The symbols " (for LD bands) and ' (for HD bands) are given where a new thin band type was formed. Corals S1 to S6 were collected from $4 \mathrm{~m}$ depth; corals $\mathrm{G} 1$ to $\mathrm{G} 6$ were collected from 8 to $12 \mathrm{~m}$ depth; and coral $Z 4$ from $20 \mathrm{~m}$ depth

\begin{tabular}{|c|c|c|c|c|}
\hline \multicolumn{5}{|c|}{ Winter sampling, December-January $1986-87$} \\
\hline Coral & Type & $\begin{array}{l}\text { External band } \\
\text { width }(\mathrm{mm}) \\
\qquad(x)\end{array}$ & $\begin{array}{c}\text { Aver. } \pm \text { SD of } \\
\text { LD width }(\mathrm{mm}) \\
(y)\end{array}$ & $\begin{array}{l}x / y \\
(\%)\end{array}$ \\
\hline G1 & new HD & Thin & - & . \\
\hline G2 & $\mathrm{LD}$ & 5.0 & $4.8 \pm 0.8$ & 104.1 \\
\hline G3 & $\mathrm{LD}$ & 6.0 & $6.6 \pm 1.4$ & 91.0 \\
\hline G7 & LD & 3.0 & $3.7 \pm 0.7$ & 81.1 \\
\hline G6 & new HD & Thin & - & . \\
\hline Z4 & new HD & Thin & - & $\cdot$ \\
\hline \multicolumn{5}{|c|}{ Summer sampling, May-June 1987} \\
\hline Coral & Type & $\begin{array}{c}\text { External band } \\
\text { width }(\mathrm{mm}) \\
\qquad(x)\end{array}$ & $\begin{array}{c}\text { Aver. } \pm \mathrm{SD} \text { of } \\
\mathrm{HD} \text { width }(\mathrm{mm}) \\
(y)\end{array}$ & $\begin{array}{l}x / y \\
(\%)\end{array}$ \\
\hline S1 & HD & 1.5 & $1.3 \pm 0.6$ & 115.4 \\
\hline $\mathrm{S} 2$ & HD & 1.0 & $1.1 \pm 0.4$ & 91.0 \\
\hline S3 & new LD & Thin & - & $\cdots$ \\
\hline S4 & HD & 1.0 & $1.2 \pm 0.3$ & 83.3 \\
\hline S5 & $\mathrm{HD}$ & 0.8 & $2.0 \pm 0.8$ & 40.0 \\
\hline S6 & new LD & 2.0 & - & $\cdots$ \\
\hline
\end{tabular}

Fig. 5 shows a suggested model for band depositional pattern of Porites species in the Gulf of Eilat, and illustrates the relationship between this pattern and exogenic and endogenic factors. The values of seawater temperature measured at $0.5 \mathrm{~m}$ depth, and light expressed in hours of sun irradiance per month, repre-

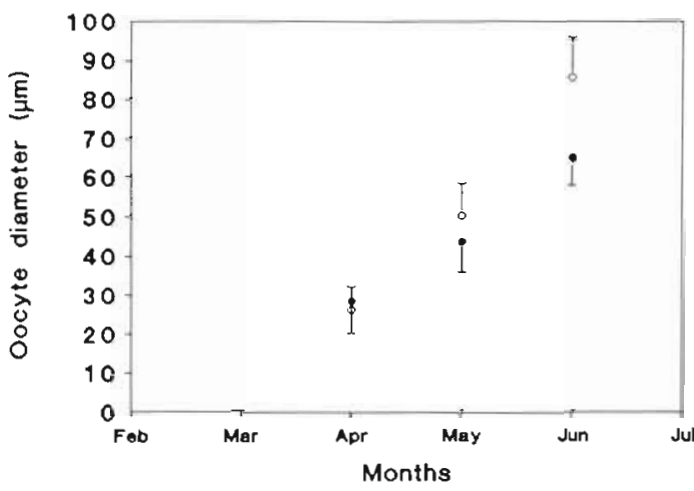

Fig. 4. Porites spp. Oocyte development during the reproductive period (March to July) of P. lobata ( $\bullet$ ) and P. columnaris (0)

sent averages of over $20 \mathrm{yr}$ (the year 1987, in which most of the corals were collected, showed similar patterns of seawater temperature and sun irradiance). The curves indicating seawater temperature and sun irradiance are given over a period of $24 \mathrm{mo}$ (Fig. 5), demonstrating the transition from one type of density band to the other. The reproductive period of the 2 Porites species is illustrated in the model with reference to Fig. 4.

\section{DISCUSSION}

The high variability in the linear growth rate throughout the coral life is clearly demonstrated in our results, as also shown in similar studies (Buddemeier et al. 1974, Buddemeier \& Kinzie 1976, Isdale 1977, Brown et al. 1986). Measurements of the linear increments along the coral axis indicated no significant

Table 3. Porites spp. Illustration of probable transition timing from HD band deposition to LD band deposition and vice versa, based on results in Table 2

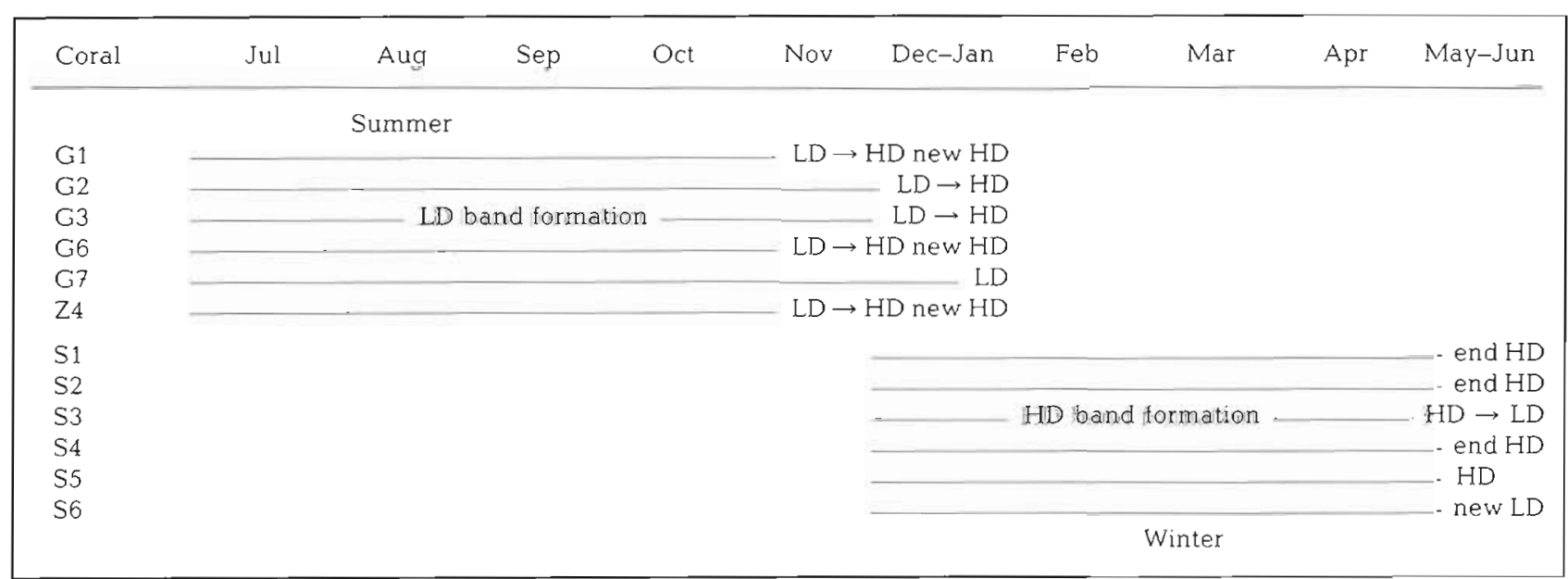




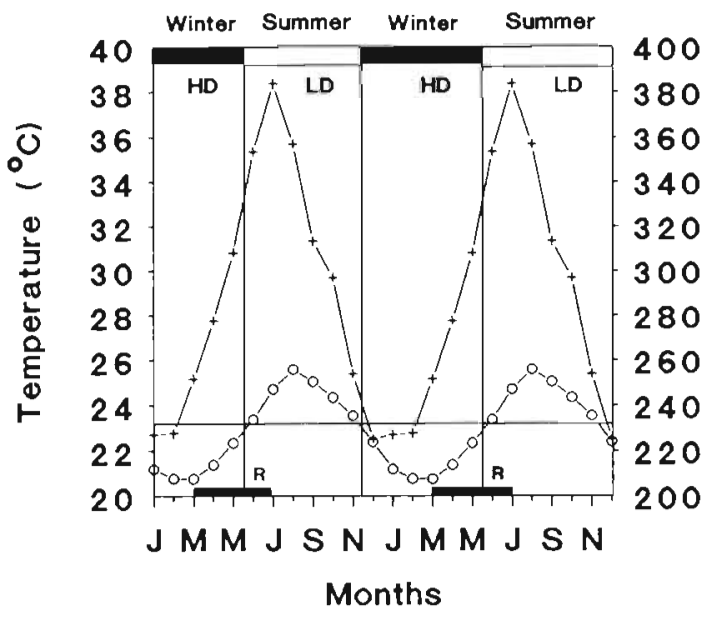

Fig. 5. A model for the seasonal deposition pattern of skeletal bands in Porites species in the Red Sea, in relation to exogenous factors (light and temperature) and an endogenous factor (reproduction). HD: high density bands; LD: low density bands; $(0)$ surface sea water temperature; $(+)$ sun irradiance $\left(\mathrm{h} \mathrm{mo}{ }^{-1}\right.$ ); R: reproductive period. Vertical lines represent the probable shift in band formation, i.e. from one type of band to the other Horizontal line represents a temperature of $23^{\circ} \mathrm{C}$ (see text for explanation)

differences among the years 1972 to 1986 (Fig. 2); i.e. within this time span the corals did not show any tendency to decrease their linear growth rate as they age or grow. This is consistent with other reports on the genus Porites (e.g. Highsmith 1979). Comparison of the regression lines of the 2 species shows that each reaches a different size ( $P$. lobata is larger than $P$. columnaris) at the same age, due to their differences in linear growth rates (Fig. 3). The average annual growth rate of $P$. lobata varies between 4 and $13 \mathrm{~mm} \mathrm{yr}^{-1}$ in different geographical reef locations (summarized in Guzman \& Cortes 1989). The maximal annual growth rate for $P$. lobata in the Gulf of Eilat did not exceed $9.5 \mathrm{~mm} \mathrm{yr}^{-1}$ (mean $7.48 \pm 1.78 \mathrm{~mm} \mathrm{yr}^{-1}$ ). This maximum value is relatively low compared to the maximum growth extension recorded for P. lobata from the Philippines (13 $\mathrm{mm} \mathrm{yr}^{-1}$; Pätzold 1984) or Eniwetok Atoll (11.5 $\mathrm{mm} \mathrm{yr}^{-1}$; Buddemeier et al. 1974).

Based on analysis of the outermost band characteristics, we found that, in the Gulf of Eilat, the wide LD coral bands of Porites species are deposited during the warm season (summer), and the HD narrow bands are deposited during the cold season (winter). An oxygen isotopic composition (ratio of ${ }^{18} \mathrm{O}:{ }^{16} \mathrm{O}$ ) study of a profile along the growth axis of $P$. lobata compared to the $X$-ray image confirmed this intra-annual depositional pattern (Klein et al. 1991). Results for the stable isotope composition of the skeletal banding indicate that the LD bands, depleted in ${ }^{18} \mathrm{O}$, are deposited during the warmest seawater temperatures and vice versa for $\mathrm{HD}$ bands.
Although the coral colonies belong to 2 different Porites species, they exhibited a synchronous intraannual banding pattern. Summer in the northern Red Sea is characterized by high water temperatures and sun irradiance values in comparison with winter (Fig. 5). Thus, the deposition of the LD portion, which exhibits a higher linear extension than the HD portion, takes place during environmental conditions of higher light irradiance and seawater temperature. The opposite occurs for HD deposition.

Deposition of LD bands during summer was reported in several places in the northern hemisphere, e.g. Oaho Island, $22^{\circ} \mathrm{N}$ (Buddemeier \& Kinzie 1975); Bermuda, $32^{\circ} \mathrm{N}$ (Dodge \& Thomson 1974), and in the southern hemisphere: Papua New-Guinea $\left(9^{\circ} \mathrm{S}\right)$ and Java Sea $\left(6^{\circ} \mathrm{S}\right)$ (Scoffin et al, 1989). Deposition of LD bands during winter occurs both in the northern hemisphere: Eniwetak $\left(11^{\circ} \mathrm{N}\right)$, Jamaica $\left(18^{\circ} \mathrm{N}\right)$ and Panama $\left(8^{\circ} \mathrm{N}\right)$ (Buddemeier et al. 1974, Dodge 1978, Wellington \& Glynn 1983, respectively), and the southern hemisphere: Fairy Reef, $19^{\circ} \mathrm{S}$ (Isdale 1977). For a detailed account see Highsmith (1979) and Lough \& Barnes (1990). Porites corals from Eilat, Red Sea $\left(29^{\circ} \mathrm{N}\right)$ deposit LD bands during summer and HD bands during winter, in a similar pattern to corals from Bermuda and Hawaii.

Several models have been suggested concerning the major factors controlling band formation in corals. Highsmith (1979) categorized scleractinian corals into 3 major groups according to the similarity in their banding pattern relative to light availability and seawater temperature. He employed the term 'high latitude' for groups of corals exhibiting LD band formation during periods of high light availability and high temperatures, and HD band formation during periods of low light availability and low temperatures. As light intensity and seawater temperature in the present study area are both high in summer and low in winter, Red Sea Porites corals thus fit within Highsmith's (1979) 'high latitude' model of coral band formation.

In several places, where light and temperature curves are in opposite phases, the LD bands are deposited during winter (see Highsmith 1979). However, the banding pattern of Porites corals demonstrated in Scoffin et al. (1989) precludes the construction of a simple universal model, by showing deposition of LD bands during summer.

Lough \& Barnes (1990) discussed serveral exceptions, as in our case, to the concept that HD bands correspond to summer time. They state that more care is required in judging the position of a chemical skeletal marker relative to the density banding pattern, due to geometric discrepancies between skeletal slices and Xradiographs. In our study, the seasonal banding pattern was independently determined by (1) analysis of the outermost bands in the X-ray images (Tables $2 \& 3$ ) and 
(2) comparison of a density profile with the oxygen isotopic composition $\left({ }^{18} \mathrm{O}\right.$ ) of coral skeleton (Klein et al. 1991). Results from these 2 methods assure a substantially reliable determination of band deposition timing in Red Sea Porites corals. The exceptional pattern (LD = summer and $\mathrm{HD}=$ winter) is probably due to environmental factors, rather than coral geometry.

Fig. 5 shows a shift from LD to HD in NovernberDecember. During these months the water temperature begins to decline below a value of $23^{\circ} \mathrm{C}$, while light values are already at their lowest. In contrast, the shift from HD to LD bands takes place in May-June, when the water temperature begins to rise above $23^{\circ} \mathrm{C}$, and the light values almost reach their maxima. It is suggested that this combination of average thresholdtemperature with the respective light levels (high or low) is significant in dictating the annual density pattern. We therefore support the hypothesis of Highsmith (1979) and Schneider \& Smith (1982) that a combination of light and temperature plays a major role in controlling the nature of skeletal density banding in corals. However, since light and temperature changes are highly correlated in our study area, we cannot at this time isolate the relative importance of one over the other. A controlled experiment in which one of these factors is held constant, while the other varies, is necessary for further proof.

Reproduction took place between March and July, with a peak of oocyte mean diameter in June (Fig. 4). Like many other invertebrates, and especially Red Sea corals (Shlesinger \& Loya 1985), the reproduction period in both Porites species is mainly linked to the beginning of water temperature rise during March (average value $21^{\circ} \mathrm{C}$; Fig. 5). The increase in oocyte diameter extends over periods when the corals produce both HD and LD skeletal bands. In both Porites species the oocytes first appear in March, when the coral is in the middle of the period of deposition of narrow $\mathrm{HD}$ bands (during $3 \mathrm{mo}$ at least). Furthermore, a major increase in oocyte diameter (i.e. energetic expenditure) occurs just after the transition from HD to LD bands (Figs. 4 \& 5). We therefore suggest that skeletal density pattern in Porites corals in the Red Sea is mainly dictated by physical factors (water temperature and light), while endogenic factors, such as reproduction, are probably of lesser importance in this process.

Acknowledgements. We thank Mrs O. Leshem of Ichilov Hospital, Tel Aviv, for supplying the X-radiography facilities. We also thank $\mathrm{Mr} \mathrm{A}$. Vinkler for sample preparation and technical assistance. Special thanks are due to 2 anonymous referees who greatly improved the manuscript. This research was supported by a grant from the National Council for Research and Development, Israel, and the Ministry of Science and Technology (MOST) (Joint German-Israeli Research Program).

\section{LITERATURE CITED}

Barnes, D. J., Lough, J. M. (1989). The nature of skeletal density banding in scleractinian corals: fine banding and seasonal patterns. J. exp. mar Biol. Ecol. 126: 119-134

Brown, B., Le Tissier, M., Howard, L. S., Charuchinda, M. Jackson, J. A. (1986). Asynchronous deposition of dense skeletal bands in Porites lutea. Mar. Biol. 93: 83-89

Buddemeier, R. W., Kinzie, R. A. (1975). The chronometric reliability of contemporary corals. In: Rosenberg, G. D., Runcorn, S. K. (eds.) Growth rhythms and the history of the earth's rotation. Wiley, London, p. 135-146

Buddemeier, R. W., Kinzie, R. A. (1976). Coral growth Oceanogr. mar. Biol. A. Rev. 14: 183-225

Buddemeier, R. W., Maragos, J. E., Knutson, D. W. (1974) Radiographic studies of reef coral exoskeletons: rates and patterns of coral growth. J. exp. mar Biol. Ecol. 14 $179-200$

Dodge; R. E. (1978). The natural growth records of reef building corals. Ph.D. thesis, Yale University

Dodge, R. E., Thomson, J. (1974). The natural radiochemical and growth records in contemporary hermatypic corals from the Atlantic and Caribbean. Earth planet. Sci. Lett 23: $313-322$

Dodge, R. E., Vaisnys, J. R. (1975). Hermatypic coral growth banding as environmental recorder. Nature, Lond. 258: 706-708

Dodge, R. E., Vaisnys, J. R. (1980). Skeletal growth chronologies of recent and fossil corals. In: Rhoads, D. C., Lutz, R. A. (eds.) Skeletal growth of aquatic organisms. Plenum Press, New York, p. 493-517

Guzman, H. M., Cortes, J. (1989). Growth rates of eight species of scleractinian corals in the eastern Pacific (Costa Rica). Bull. mar Sci. 44(3): 1186-1194

Highsmith, R. C. (1979). Coral growth rates and environmental control of density banding. J. exp. mar Biol. Ecol. 37: 105-125

Hudson, J. H., Shinn, E. A., Halley, R. B., Lidz, B. (1976). Sclerochronology: a tool for interpreting past environments. Geology 4: 361-364

Isdale, P. (1977). Variation in growth rate of hermatypic corals in a uniform environment. Proc. Third Int. Coral Reef Symp., Vol. 1: 403-408

Knutson, D. W., Buddemeier, R. W., Smith, S. V. (1972). Coral chronometers: seasonal growth bands in reef corals. Science 177: 270-272

Klein, R., Pätzold, J., Wefer, G., Loya, Y (1991). Seasonal variations in the stable isotopic composition and the skeletal density pattern of the coral Porites lobata (Gulf of Eilat, Red Sea). Mar. Biol. (in press)

Lough, J. M., Barnes, D. J. (1990). Intra-annual timing of density band formation of Porites coral from the central Great Barrier Reef. J. exp. mar. Biol. Ecol. 135: 35-57

Loya, Y (1976). The Red Sea coral Stylophora pistillata is an r strategist. Nature, Lond. 259: 478-480

Loya, Y., Slobodkin, L. B. (1971). The coral reefs of Eilat (Gulf of Eilat, Red Sea). Symp. Zool. Soc. Lond. 28: 117-139

Macintyre, I. G., Smith, S. V (1974). X-radiographic studies of skeletal development in coral colonies. Proc. Second Int. Coral Reef Symp. 2: 277-287

Moore, W. S., Krishnaswami, S. (1974). Correlation of Xradiography revealed banding in corals with radiometric growth rates. Proc. Second Int. Coral Reef Symp. 2 269-276

Pätzold, J. (1984). Growth rhythms recorded in stable isotopes and density bands in the reef coral Porites lobata (Cebu, Philippines). Coral Reefs 3: 87-90 
Rinkevich, B., Loya, Y. (1979). The reproduction of the Red Sea coral Stylophora pistillata. I. Gonads and planulae. Mar. Ecol. Prog. Ser. 1: 133-144

Schneider, R. C., Smith, S. V (1982). Skeletal Sr content and density in Porites spp. in relation to environmental factors. Mar. Biol. 66: 121-131

Scoffin, T. P., Tudhope, A. W. Brown, B. E. (1989). Fluorescent and skeletal density banding in Porites lutea from Papua New Guinea and Indonesia. Coral Reefs 7: 169-178

Shlesinger, Y., Loya, Y. (1985). Coral community reproductive

This article was submitted to the editor patterns: Red Sea versus the Great Barrier Reef. Science 228: $1333-1335$

Weber, J. N., White, E. W., Weber, P. H. (1975). Correlation of density banding in reef coral skeletons with environmental parameters: the basis for interpretation of chronological records preserved in the coralla of corals. Paleobiol. 1: $137-149$

Weilington, G. M. Glynn, P. W (1983). Environmental influences on skeletal banding in Eastern Pacific (Panama) corals. Coral Reefs 1: 215-222

Manuscript first received: February 5, 1991

Revised version accepted: September 4, 1991 